\section{Comparisons of Scion/rootstock Growth Rates among U.S. Pistachio Cultivars}

\author{
Craig E. Kallsen ${ }^{1}$ \\ University of California Cooperative Extension, Kern County, 1031 S. Mt. \\ Vernon Avenue, Bakersfield, CA 93307
}

\author{
Dan E. Parfitt \\ Department of Plant Sciences, MS2, University of California, One Shields \\ Avenue, Davis, CA 95616
}

Additional index words. graft union, Pistacia integerrima Stewart, Pistacia vera, UCB1, scion/rootstock ratio

\begin{abstract}
Scion and rootstock circumferences of seven male and 26 female cultivars or potential cultivars of pistachio trees (Pistacia vera $\mathrm{L}_{\text {.) }}$ ) were measured at 16 locations in the San Joaquin Valley of California. The trees were of variable age and on Pistacia integerrima-type or UCB1 (a $P$. atlantica Desf. $\times P$. integerrima Stewart hybrid) rootstock. Differences were found in the ratio of scion to rootstock circumference (SRR) between the standard industry female cultivar Kerman and the other cultivars collectively. 'Kerman' produced a smoother trunk with a SRR closer to one than other cultivars. The SRR was also affected by rootstock with values closer to one for UCB1 as compared with higher values for $P$. integerrima rootstocks. The relationship between SRR and tree age demonstrated here can be a tool for comparing, evaluating, and selecting new rootstocks with growth rates to match those of newly developed or introduced scion cultivars.
\end{abstract}

Similar scion and rootstock growth rates produce strong graft unions in fruit and nut trees. A SRR close to one provides a strong graft union as well as a uniform exterior surface for trunk-shaking harvesters. 'Kerman', which has been the standard pistachio industry female cultivar for many years, produces a scion that increases in trunk circumference faster than that of the rootstocks commonly used in the San Joaquin Valley of California. Typically, a trunk shaker harvests four to six trees per minute. The rapid clamping and unclamping of the shaker head is less efficient and can produce trunk damage, called "barking," if it connects with an uneven graft union (Adrian et al., 1965; Affeldt et al., 1988, 1989; Fridley et al., 1970; Mobli and Rajabipour, 2005). For this reason, general recommendations have suggested that trees should not be grafted below $400 \mathrm{~mm}$ from the ground where harvest shakers typically grasp the tree (Beede et al., 2008; Coe Orchard Equipment, personal communication). However, unlike most other fruit and nut trees, pistachio rootstocks are first planted in the field during late winter and scion grafted,

Received for publication 27 Sept. 2010. Accepted for publication 22 Nov. 2010

This research was conducted as a project of the University of California Agricultural Experiment Station, University of California Cooperative Extension, and carried out in part with funding from the California Pistachio Research Board. We thank both Louise Ferguson and John Karlik for their valuable suggestions toward improving the manuscript.

${ }^{1}$ To whom reprint requests should be addressed; e-mail cekallsen@ucdavis.edu. by t-budding (also known as shield budding), in July or August (Beede et al., 2008). Frequently, the diameter of the rootstock trunk is too small to place the scion bud above the height that will be in the zone of shaker attachment. Identifying scion rootstock combinations that produce smoother graft unions would reduce bark damage and improve harvester efficiency through more rapid attachment to the trunk.

As trees age, differences in the respective growth rates may result in possible incompatibility between the scion and rootstock. Although there is no evidence to suggest that pistachio tree health, growth, or yield have been affected by differences in scion/rootstock growth rates, pistachio is a long-lived tree and the oldest trees of the scion/rootstock combinations pioneered in the United States are only 30 years old (Ferguson et al., 2008). The causes of graft incompatibility in woody plants remain poorly defined (Andrews and Marquez, 1993; Santamour, 1988). In stone fruit trees, smoother graft unions have been associated with greater tree longevity (Kester et al., 1964; Tshokoeva and Tsonev, 1995). Schneider and Pehrson (1985) found that the smoother bud unions of 21-year-old 'Frost Nucellar' navel orange scion on Rubidoux trifoliate rootstock as compared with Pomeroy trifoliate rootstock were consistent with better phloem organization and tree health. Generally, in woody perennial plants, a smooth trunk through the graft union appears to be a desirable trait (Beckman et al., 2008) and overgrowth is a concern (Nessel and Gruppe, 1985; Wagner and Gruppe, 1985).
Scion cultivars are Pistacia vera L. and in the United States are grafted almost exclusively to Pistacia integerrima rootstock or UCB1, which is a Pistacia atlantica $\times P$. integerrima hybrid. These rootstocks are chosen because of $P$. integerrima resistance to soilborne Verticillium wilt (Verticillium dahliae Kleb.) and its ability to produce a rapidly growing, early-fruiting tree (Ferguson, et al., 2002, 2008). P. integerrima rootstocks have a longer history in U.S. production than UCB1 with the first use in 1980. UCB1 was first introduced commercially in 1989. The female cultivar Kerman and the male pollenizer 'Peters' are the primary cultivars grown in California. Newer scion cultivars are important to the industry for extension of the harvest season, pest avoidance, nut quality, and yield. These alternative $P$. vera cultivars have been reported to show increased scion overgrowth compared with 'Kerman' when grafted to existing commercial rootstocks with $P$. integerrima parentage. Little information is available in the literature on how SRR changes with time for any woody perennial. The ratio of the circumference of the scion to that of the rootstock has been used to measure equality in growth rate of the scion and rootstock in citrus, grapes, avocado, and other woody crops (Emmanuelli and Clingeleffer, 2006; Mickelbart et al., 2007; Roose et al., 1989).

The objective of the present analysis was to quantify differences, if any, in the SRR of 'Kerman' and new and potential female cultivars. Differences in growth rate of scion and rootstock were measured for a number of $P$. vera cultivars on $P$. integerrima or UCB1 rootstocks of different ages at multiple sites in the southern San Joaquin Valley of California to validate these observations and demonstrate the significance of any observed differences. A further objective was to identify other variables affecting the magnitude of the SRR for the purpose of producing a tree with a more uniform circumference through the graft union.

\section{Materials and Methods}

Plant material and measurements. Scion and rootstock circumferences of seven male and 26 female cultivars or potential cultivars were measured at 16 locations in the southern San Joaquin Valley of California. Thirteen were in Kern County, two in Tulare County, and one in Madera County. These locations include most of the soils and climatic zones where pistachios are grown within the southern San Joaquin Valley. Verticillium wilt is endemic in this area and most commercial plantings of pistachio since 1980 were planted on Verticillium wilt-resistant rootstocks (Epstein et al., 2004). All of the individually measured 709 female trees and 119 male trees were grafted onto one of four rootstocks resistant to Verticillium wilt disease. These resistant rootstocks were: 1) $\operatorname{UCB} 1(P$. atlantica $\times P$. integerrima $)$; 2) a commercially available cloned UCB1; 3) PG1 ( $P$. integerrima); or 4) an unnamed $P$. integerrima rootstock no longer commercially 
available. Measurements were made in commercial orchards and in randomized and replicated advanced-selection cultivar evaluation trials. Several commercial orchards were planted to two or more cultivars, including Kerman, on two different rootstocks, growing under similar cultural and environmental conditions. Seven of the 16 locations were designed as cultivar evaluation trials, which contained 'Kerman' and as many as 10 other cultivars or potential cultivars, and two of these sites included replicated trials on UCB1 and PG1.

The graft unions of pistachio trees are often not parallel to the ground, and the trunk in this area may be irregular. Scion circumference was measured $10 \mathrm{~mm}$ above the graft union because the largest circumference of the scion occurred immediately above this point of connection. This measurement was made horizontally, parallel to the ground, at the highest point of the graft union aboveground level The area of the trunk immediately below the graft union tended to be rough, creased, tapered, and the graft union was not always horizontal to the ground

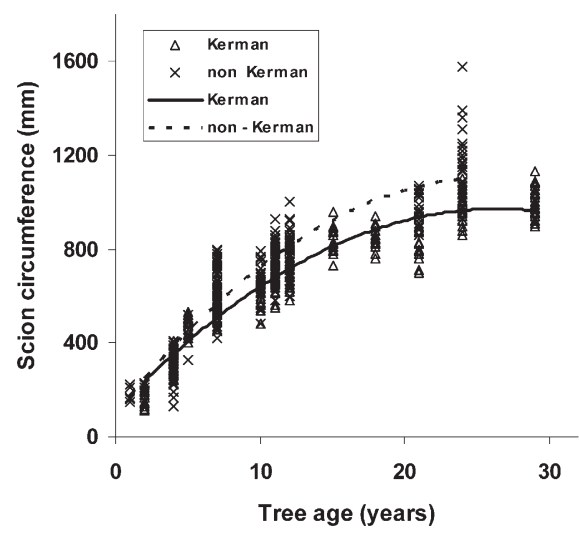

Fig. 1. The relationship between tree age and scion circumference of 'Kerman' $\left(\mathrm{y}=-1.2395 \mathrm{x}^{2}+\right.$ $\left.65.35 \mathrm{x}+110.44 ; r^{2}=0.90\right)$ and non-'Kerman' $\left(\mathrm{y}=-1.4739 \mathrm{x}^{2}+77.21 \mathrm{x}+96.05 ; r^{2}=0.87\right)$ female cultivars in the San Joaquin Valley.

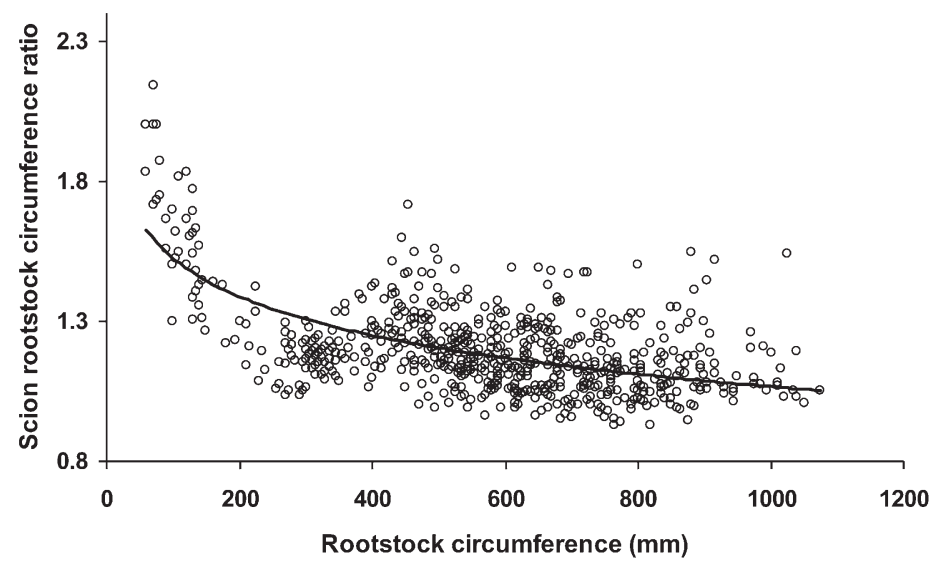

Fig. 2. The relationship between rootstock circumference and the scion/rootstock circumference ratio for individual female pistachio trees of all measured cultivars in the San Joaquin Valley $[y=-0.1991$ $\left.\ln (\mathrm{x})+2.44 ; r^{2}=0.40\right]$.

surface. To ameliorate this non-uniformity, the circumference of the rootstock was measured at two points, 100 and $150 \mathrm{~mm}$ below the highest point of the graft union aboveground level. The SRR is the scion circumference divided by the mean of the two rootstock circumferences. Additional data collected for each tree included the following: name of cultivar or selection, sex, date planted, rootstock cultivar, and distance from the lowest point of the graft union to the ground surface.

Statistical analyses. Data were analyzed using analysis of variance and multiple regression statistical packages in Statistica software (StatSoft, Inc., Tulsa, OK). Multiple regression analysis was used to evaluate the relationship between SRR (the dependent variable) and associated variables measured in the field (the independent variables). Variables included in the multiple regression analyses were selected from scatterplot results of independent variables plotted against SRR. Both rootstock circumference and tree age were correlated with SRR. Multicollinearity among independent variables was avoided by retaining variables that demonstrated higher simple correlations with SRR than other variables. Other variables included the species composition of the rootstock, either UCB1 hybrids (arbitrarily assigned a value of 0 ) or $P$. integerrima (assigned a value of 1 ), and whether the variety was 'Kerman' (arbitrarily assigned a value of 0 ) or "not 'Kerman", and assigned a value of 1 . The first- and second-degree polynomial iterations and natural logarithms of all variables were included in the regression analyses because some relationships in the scatterplots appeared curvilinear. Interaction terms, selected as described previously, were also entered into the regression.

\section{Results and Discussion}

Scion circumference. Scion circumferences of 'Kerman' trees of a given age and grafted on $P$. integerrima and UCB1 rootstocks were less than for other female culti- vars (Fig. 1). These scion and rootstock combinations have only been grown for a maximum period of 30 years in the United States, where they were developed, and the eventual size of the trunk and rootstock is unknown.

Rootstock circumference. Tree age and rootstock circumference were highly positively correlated for female cultivars (adjusted $r^{2}=0.77$ ). Correlations between various independent variables, including SRR, with tree age showed greater variability than correlations with rootstock circumference (data not shown), probably because increases in rootstock circumference more adequately reflect growth limitations of soils, fertilization, irrigation, weather, and other factors than tree age.

Scion/rootstock circumference ratio. A scatterplot of rootstock circumference versus SRR of each measured female tree demonstrates the curvilinear nature of the relationship and the range of SRR represented (Fig. 2 ). SRRs were greater for trees with rootstock circumferences less than $200 \mathrm{~mm}$ (i.e., 1- or 2 -year old trees), although values greater than 1.5 were not unusual for older trees with large rootstock circumferences (Fig. 2).

Variables useful in explaining differences in scion to rootstock circumference. In general, interaction terms between and among variables did little to explain much of the variation in the regression and for simplicity were removed from subsequent regression analyses.

SRR was greater for non-'Kerman' cultivars regardless of rootstock and were greater for $P$. integerrima rootstocks than for UCB1 regardless of scion cultivar (Table 1). At any given value of the rootstock circumference, the scion circumference was greater for non-'Kerman' cultivars than for 'Kerman' on the $P$. integerrima rootstocks (Fig. 3 ). The greater variability in the relationship between scion circumference and rootstock circumference of non-'Kerman' cultivars $\left(r^{2}=0.87\right)$ compared with 'Kerman' $\left(r^{2}=0.96\right.$, Fig. 3) on $P$. integerrima rootstocks was in part the result of collectively including all of the non-'Kerman' cultivars together in the analysis.

The difference between the scion and rootstock circumferences of a tree are less between 'Kerman' and the other cultivars when on UCB1 (Fig. 3B) than when on $P$. integerimma (Fig. 3A). With increasing UCB1 rootstock circumference, scion circumference more closely matches that of the rootstock, creating, on average, a smoother trunk with time (Figs. 3B and 4). Average SRR for non-'Kerman' trees with rootstock circumferences greater than $200 \mathrm{~mm}$ (i.e., trees older than 2 years) were significantly different between $P$. integerrima and UCB1 with values of 1.26 and 1.17 , respectively (by $t$ test, $\mathrm{n}=262, P<0.00000$ ). This difference in the relationship between rootstock circumference and SRR for 'nonKerman' cultivars on either UCB1 or $P$. integerrima rootstocks is apparent in the scatterplot of individual tree data points 
Table 1. Multiple regression summary of significant independent variables regressed against scion/ rootstock circumference ratio (SRR) of all female trees. ${ }^{2}$

\begin{tabular}{lrcccc}
\hline Variable & Beta & SE of beta & \multicolumn{1}{c}{ B } & SE of B & $P$ level \\
\hline Intercept & & & 2.36428 & 0.097 & $<1 \times 10^{-6}$ \\
Kerman or not-Kerman $^{y}$ & 0.2793 & 0.027 & 0.09624 & 0.009 & $<1 \times 10^{-6}$ \\
Rootstock species composition $^{\mathrm{x}}$ & 0.3493 & 0.029 & 0.12792 & 0.011 & $<1 \times 10^{-6}$ \\
Ln (rootstock circumference, $\mathrm{mm}$ ) $^{-0.7210}$ & 0.030 & -0.23105 & 0.010 & $<1 \times 10^{-6}$ \\
Ln (graft distance to ground, mm) & 0.0650 & 0.029 & 0.02139 & 0.010 & 0.028 \\
\hline
\end{tabular}

$\mathrm{z}_{\mathrm{n}}=709$, adjusted $r^{2}=0.55$.

y‘Kerman' trees were assigned a value of 0 , wherease any cultivar that was not 'Kerman' was assigned a value of 1 .

${ }^{\mathrm{x}}$ The $P$. atlantica $\times P$. integerrima hybrid UCB1 was assigned a value of 0 and all $P$. integerrima rootstocks a value of 1 .
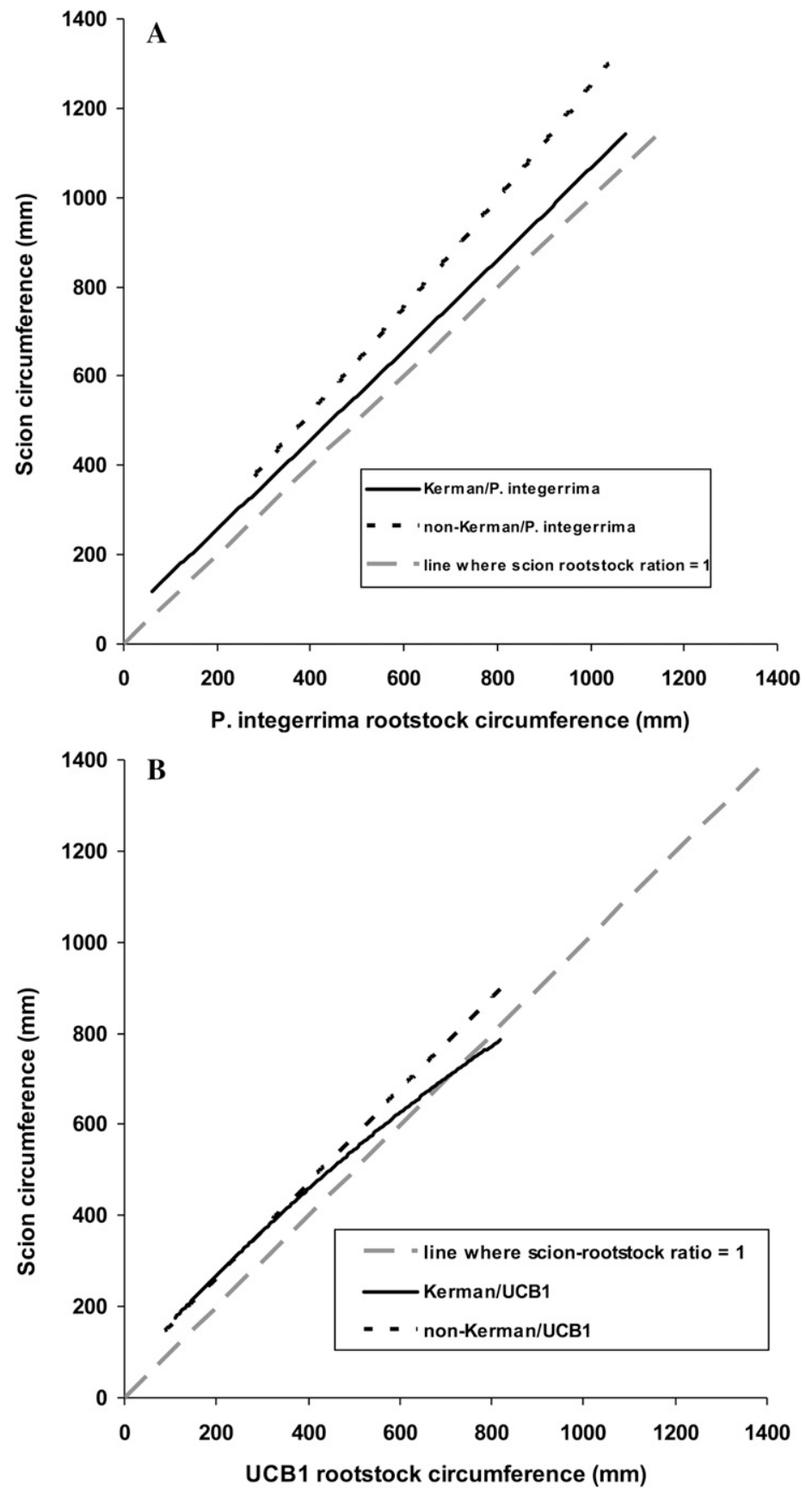

Fig. 3. (A) Relationship between rootstock circumference and the scion circumference of individual 'Kerman' trees $\left(\mathrm{y}=0.00002 \mathrm{x}^{2}+0.985 \mathrm{x}+58.69 ; r^{2}=0.95\right)$ or female cultivars other than 'Kerman' $(\mathrm{y}=$ $\left.0.00010 \mathrm{x}^{2}+1.0873 \mathrm{x}+64.91 ; r^{2}=0.87\right)$ on $P$. integerrima rootstocks. (B) Relationship between rootstock circumference and the scion circumference of individual 'Kerman' trees $\left(\mathrm{y}=0.00027 \mathrm{x}^{2}+\right.$ $\left.1.108 \mathrm{x}+57.16 ; r^{2}=0.98\right)$ or female cultivars other than 'Kerman' $\left(\mathrm{y}=-0.00004 \mathrm{x}^{2}+1.065 \mathrm{x}+50.69\right.$; $\left.r^{2}=0.97\right)$ on UCB1 rootstocks.
(Fig. 4). However, the variability present in SRR, whether on $P$. integerrima or UCB1 rootstocks, was high (Fig. 4) with SRR values for trees with rootstock circumferences greater than $350 \mathrm{~mm}$ ranging from 1 to greater than 1.50 for $P$. integerrima and greater than 1.25 for UCB1. This variability suggests that efforts to develop new rootstock types with smoother graft unions are worthwhile in addition to seeking further improvements in yield, fruit quality, disease resistance, and cold and salt tolerance. The function relating SRR to rootstock circumference for UCB1 displayed in Figure 4 would be a useful comparative measurement tool in a rootstock breeding program. Breeders would seek to produce a new rootstock with a smaller SRR for a given rootstock circumference than UCB1. An advantage of using the function displayed in Figure 4 is that breeders would be able to compare experimental rootstock SRR values with UCB1, initially, when trees were very young for an early indication of this performance characteristic.

Males, other than 'Peters', the industry standard male cultivar, also demonstrated greater SRR than 'Peters' (data not shown). However, male trees are not shaken and therefore do not present a problem with respect to "barking," although longevity may remain a concern.

The distance from the ground to the graft union varied from 160 to $1120 \mathrm{~mm}$. The SRR was greater for all cultivars and rootstock as distance from the tree graft union to the ground increased (Table 1). However, the variability present in the relationship and flat response curve between graft distance and SRR (Fig. 5) suggests that this variable has limited use in improving SRR with existing rootstocks. The feasibility of lowering grafting height must also be balanced with the need to minimize placement of the graft union in the area of the attachment of the shaker to the trunk and not so low that disking and other farm operations might bury the graft union.

\section{Conclusions}

The pistachio industry has used only 'Kerman' as a female cultivar. Only recently as new cultivars have reached bearing age has the difference in growth rates of 'Kerman' versus other cultivars become apparent. Currently, the rootstocks used in pistachio production in the United States produce SRRs greater than one. Non-'Kerman' cultivars show greater SRRs than 'Kerman' on $P$. integerrima rootstocks. Non-'Kerman' cultivars have smaller SRRs on UCB1 rootstock than on $P$. integerrima rootstocks. The degree of variability in the SRRs of non-'Kerman' cultivars, whether on $P$. integerrima or UCB1 rootstocks, suggests that efforts toward developing a rootstock with a growth rate that more closely matches that of newer $P$. vera scions would be of benefit to the pistachio industry. 


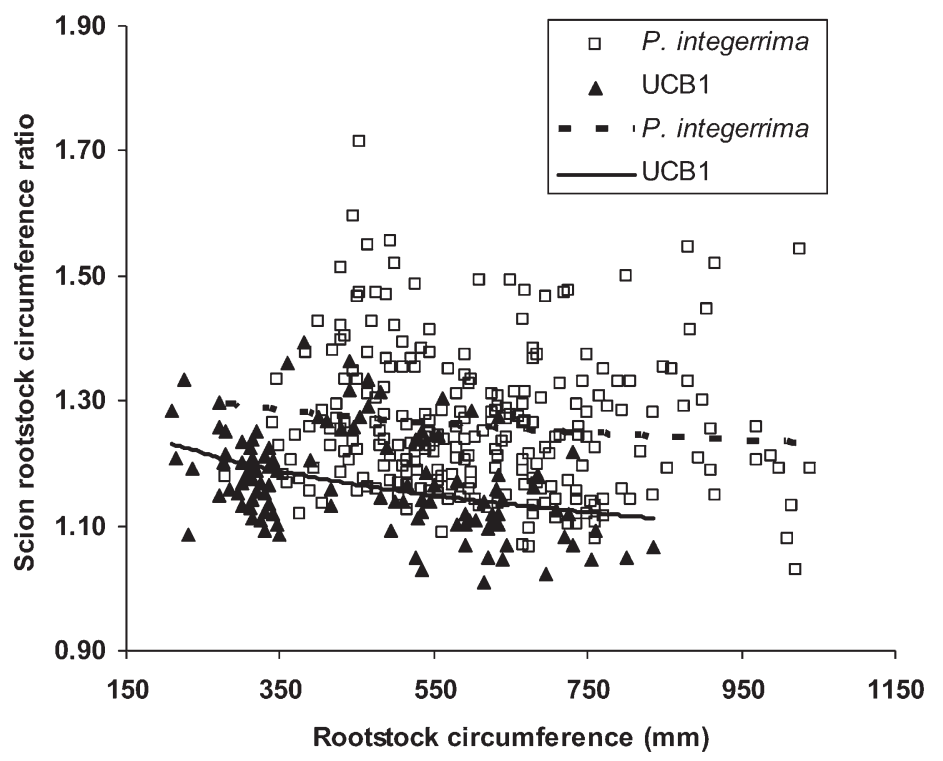

Fig. 4. Relationship between rootstock circumference and the scion/rootstock circumference ratio for individual non-'Kerman' pistachio trees with circumferences greater than $200 \mathrm{~mm}$ on either UCB1 [y $=$ $\left.-0.049 \ln (\mathrm{x})+1.69 ; r^{2}=0.144\right]$ or $P$. integerrima $\left[\mathrm{y}=-0.086 \ln (\mathrm{x})+1.57 ; r^{2}=0.012\right]$ rootstocks.

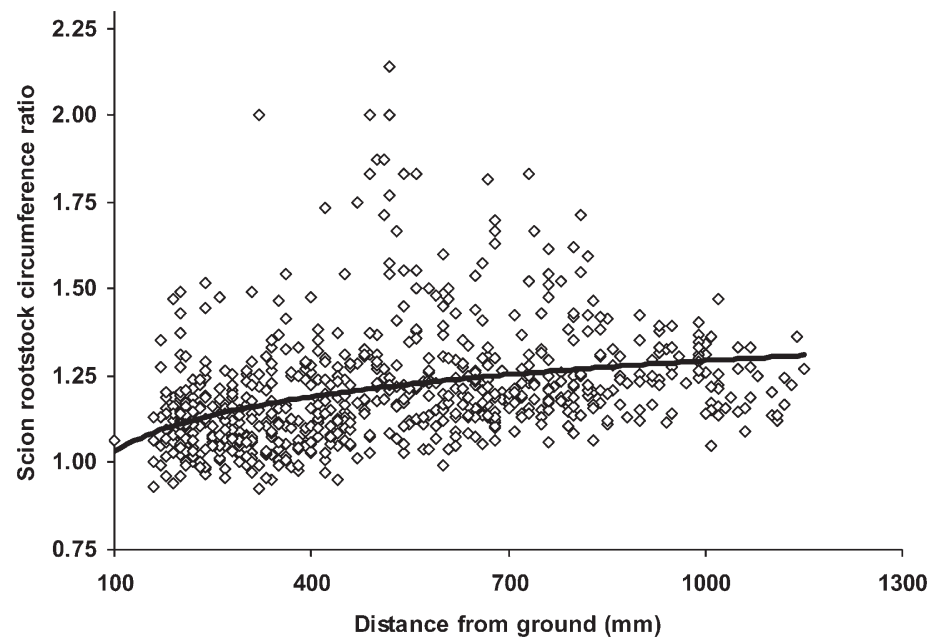

Fig. 5. The relationship between graft distance from the ground and the scion/rootstock circumference ratio for individual female pistachio trees in the San Joaquin Valley $\left[\mathrm{y}=0.1128 \ln (\mathrm{x})+0.51 ; r^{2}=0.12\right]$.

\section{Literature Cited}

Adrian, P.A., R.B. Fridley, D.H. Chaney, and K. Uriu. 1965. Shaker-clamp injury to fruit and nut trees. Calif. Agr. 19:8-10.

Affeldt, H.A., Jr., G.K. Brown, and J.B. Gerrish 1989. A new shaker for fruit and nut trees. J. Agr. Eng. Res. 44:53-66.
Affeldt, H.A., Jr., G.K. Brown, J.B. Gerrish, and T.A. Esch. 1988. Elimination of adverse dynamic loader shaking on nut and fruit trees. Trans. ASABE. 31:1649-1663.

Andrews, P.K. and C.S. Marquez. 1993. Graft incompatibility. Hort. Rev. (Amer. Soc. Hort. Sci.) 15:183-231.
Beckman, T.G., J.X. Chaparro, and W.B. Sherman. 2008. 'Sharpe', a clonal prune rootstock for peach. HortScience 43:2236-2237.

Beede, R.H., C.E. Kallsen, B.A. Holtz, L. Ferguson, K. Klonsky, and R.L. De Moura. 2008. Sample costs to establish and produce pistachios, San Joaquin Valley south, low volume irrigation. PIVS-08. U.C. Cooperative Extension. Dept. of Agricultural and Resource Economics, University of California, Davis, CA.

Emmanuelli, D.R. and P.R. Clingeleffer. 2006. An assessment of rootstocks for Sunmuscat ('Vitis vinifera' L.): A new drying variety. Aust. J. Grape Wine Res. 12:135-140.

Epstein, L., R. Beede, S. Kaur, and L. Ferguson. 2004. Rootstock effects on pistachio trees grown in Verticillium dahliae-infested soil. Phytopathology 94:388-395.

Ferguson, L., R.H. Beede, H. Reyes, and P. Metheney. 2002. California pistachio rootstock evaluations. Acta Hort. 591:63-66.

Ferguson, L., H. Reyes, B. Sanden, S. Grattan, L. Epstein, and B. Krueger. 2008. Pistachio rootstocks, p. 71-77. In: Ferguson, L. (ed.). Pistachio production manual. Omnipress, Madison, WI.

Fridley, R.B., G.K. Brown, and P.A. Adrian. 1970. Strength characteristics of fruit tree bark. Hilgardia 40:205-223.

Kester, D.E., C.J. Hansen, and C. Panetsos. 1964. Effect of scion and interstock variety on incompatibility of almond on Marianna 2624 rootstock. J. Amer. Soc. Hort. Sci. 86:169177.

Mickelbart, M.V., G.S. Bender, G. Witney, C. Adams, and M.L. Arpaia. 2007. Effects of clonal rootstocks on 'Hass' avocado yield components. J. Hort. Sci. Biotechnol. 82:460466.

Mobli, H. and A. Rajabipour. 2005. Suitable stroke and frequency for nut detachment of different pistachio varieties. Intl. Agrophysics. 19:5356.

Nessel, T. and W. Gruppe. 1985. Xylem defects at the graft unions of sweet cherry trees grafted on different rootstocks (Prunus $\times$ spp.). Acta Hort. 169:275-280

Roose, M.L., D.A. Cole, D. Atkin, and R.S Kupper. 1989. Yield and tree size of four citrus cultivars on 21 rootstocks in California. J. Amer. Soc. Hort. Sci. 114:678-684.

Santamour, F.S. 1988. Graft Compatibility in woody plants: An expanded perspective. J. Environ. Hort. 6:27-32.

Schneider, H. and J.E. Pehrson, Jr. 1985. Decline of navel orange tree with trifoliate orange rootstock. Calif. Agr. 39:13-16.

Tshokoeva, M.D. and R.V. Tsonev. 1995. Compatibility of rootstock and scion in apricot trees. Acta Hort. 384:471-475.

Wagner, H. and W. Gruppe. 1985. Swelling of scion trunk above graft unions of cherry trees. Acta Hort. 169:269-274. 